\title{
A FORMAÇÃO DE CIDADÃOS “DISTINCTOS E MORIGERADOS" NA PROVÍNCIA DO GRÃO PARÁ: 1870-1889
}

A ndresan CarlosElias Barbosa*

Resumo: 0 artigo objetiva apresentar sucintamente os resultados de um estudo mais amplo sobre 0 atendimento à criança desvalida no $\mathrm{G}$ rão Pará, destacando o I nstituto Paraense de Educandos Artífices. Tem como questão base: qual o objetivo principal do governo da Província com a fundação desse Instituto? As fontes primárias utilizadas foram: os relatórios presidenciais e dos diretores do Instituto, a legislação educacional local, minutas de oficios, e jornais que circulavam na Província à época. Os resultados revelam que o atendimento oferecido se caracterizou como mais um instrumento de consolidação dos ideais iluministas produzidos na E uropa, materializados no projeto civilizador de transformar índios e mestiços em cidadãos "distinctos e morigerados".

Palavras-chave: Província do Grão Pará. Criança desvalida. Instituto Paraense de Educandos Artífices.

\section{THE EDUCATION OF CITIZENS "OF DISTINCTION AND GOOD MAN N ERS" IN TH E GRÃO PARÁ PROVIN CE : 1870-1889.}

\begin{abstract}
The article intends to present the results of a larger study on the assistance to deprived children in Grão Pará, highlighting the Instituto Paraense de Educandos Artifices. The basic question addressed: what was the main objective of the provincial government with the foundation of this Institute? The primary sources were the reports of issued by the presidents of the Province, and the directors of the Institute, the local educational legislation, drafts of letters, and newspapers that circulated in the Province at that time. The results show that the service rendered was characterized in one more tool for consolidation of the ideals of the Enlightenment produced in Europe, embodied in the civilizing project designed to turn the indians and mestizos into citizens of distinction and good manners.
\end{abstract}

Keywords: Grão Pará Province. Deprived children. Instituto Paraense de Educandos Artífices.

* Mestre em Educação. Professor da Fundaçäo Escola Bosque, da Rede Municipal de Belém. Pesquisador do grupo ECOS/UFPA. 
Andreson Carlos Elias Barbosa

\section{IN'TRODUCÃO}

A partir de 1850, o Brasil passa por profundas alterações proporcionadas pelo contexto político de estabilidade que se constituiu no Segundo Reinado, já que, nessa época, o turbulento período das rebeliões regenciais havia passado. $\mathrm{Na}$ Amazônia, também, foi um período muito importante, principalmente por conta da exploração extensiva dos seringais e da elevação da demanda pela borracha, no mercado internacional; da introdução da navegação a vapor; da chegada dos imigrantes nordestinos.

Nesse contexto, torna-se central, do ponto de vista histórico e cultural, a preocupação com a construção da identidade nacional e com o desenvolvimento e o progresso do pás, o que provocou a implantação de medidas importantes, de grande impacto social. A educação era uma dessas medidas consideradas imprescindiveis para se atingir os objetivos desejados. José Veríssimo, homem das letras e político paraense, defendia que a educação era uma condição inalienável para garantir "a superação de traços degenerescentes das raças que predominavam na conformação do tipo humano miscigenado dominante nesse espaço geográfico - o caboclo" (ARAÚJO, 2007, p.11).

Por conta desses propósitos, nas décadas finais do século XIX, assistese à criação de diversas instituições visando ao atendimento educacional, principalmente da população pobre. 0 objetivo era educar para se alcançar uma nação transformada e regenerada, capaz de formar o indivíduo para nova realidade social a ser construida, ordenada pelo Estado e pensada por intelectuais que julgavam o Brasil um país desorganizado, principalmente quando comparado às nações do mundo civilizado (GONDRA, 2002). As instituições criadas convergiam em direção a um objetivo básico: civilizar as camadas mais amplas da população.

Dentre as iniciativas, destaca-se a criação dos Institutos. Estabelecimentos que, além de funcionarem como instituições de acolhimento e disciplinamento, com forte presença dos pressupostos higienistas, de intenso moralismo e religiosidade, tinham como propósito oferecer assistência às crianças desvalidas, proporcionando-lhes, além do ensino teórico, a educação profissional com vistas à formação de cidadãos úteis a si e à nação.

O Brasil teve internatos, desde os tempos coloniais, mas é a partir do Segundo Reinado que eles assumem um papel de destaque na realidade nacional, com função política mais definida. Para Bezerra Neto (1998, p.189), o investimento na construção dessas instituições representava "a materialização dos anseios de vários grupos sociais que vivenciavam as transformações ocorridas na sociedade paraense, a partir das últimas décadas do século XIX, embalados na crença do progresso social e moral dos povos".

248

Ver a E ducação, v. 12, n. 2, p. 247- 270, jul./ dez. 2011 
A intenção era a de que os asilos e instituições desse gênero atendessem ao público que antes recorria às Santas Casas de Misericórdia e, principalmente, às Rodas dos Expostos; isto é, essas novas instituições atenderiam àqueles que necessitavam do "aparato jurídico-assistencial destinado a educá-los e corrigilos" (RIZZINI, 2009, p.98). A principal diferença é que ofereceriam um serviço a mais: a formação profissional, com o objetivo de constituir sujeitos capazes de desenvolver uma ocupação favorável ao mercado. I sso, no plano político, impediria a disseminação de pensamentos considerados subversivos e revolucionários, especialmente no que diz respeito às propostas de mudanças de sistema de governo. Esperava-se, com isso, o aumento da riqueza do país, com o crescimento da produção e a melhoria na qualidade dos produtos fabricados e dos preços comercializados.

Foram fundadas Escolas de Aprendizes Artífices nas capitais de dez províncias do país, muitas delas situadas nas cidades nas quais, anteriormente, existiram as Casas de Órfãos ou similares, todas voltadas para o ensino de um determinado ofício mecânico, visando a educar pelo trabalho, considerado "elemento reabilitador" (MARQUES; LANGE, 2008, p.93).

\section{A JUSTIFICAÇÃO E OS FUNDAMENTOS DE UMA OBRA - O INSTITUTO PARAENSE DE. EDUCANDOS ARTÍFICFS}

Nas últimas décadas do século XIX, Belém vive uma verdadeira transformação, proporcionada, principal mente, pelos recursos advindos do ciclo gomífero. Em 1872, a capital da Província do Pará era a quarta maior cidade do Império e palco de diversificadas relações estabelecidas entre seus moradores. Segundo Guimarães (2006), o desenvolvimento da urbe belenense deveu-se, sobretudo, à resolução do problema do alagadiço do Piry, que deu à cidade um ar de reforma e causou grande transformação: "uma ampliação das fronteiras urbanas da cidade, redefinindo as áreas de habitação" (GUIMARÃES, 2006, p.48).

$O$ aterramento das áreas alagadas impulsionou, também, a implementação de outras modificações infraestruturais. A navegação a vapor, o calçamento e a iluminação das ruas, foram tentativas da elite local de construir aqui outra cidade para morar, mais agradável e condizente com a atual condição. Por isso, grande parte das modificações citadas teve o centro como espaço exclusivo de desenvolvimento.

Também os lucros com a exploração da borracha fizeram com que as elites sentissem uma necessidade, cada vez maior, de consumir supérfluos. Toda essa efervescência econômica gerou uma grande demanda por trabalhadores 
especializados para atuação nas mais diferentes áreas. Bibliografias que tratam dos oficios da época apresentam uma extensa lista das mais variadas atividades laborais praticadas pelas pessoas mais pobres que circulavam pelas ruas de Belém (principalmente na Rua dos Mercadores, ponto comercial mais importante da cidade): lavadeiras, padeiros, ambulantes diversos (vendedores de frutas, de peixes, de artefatos de madeira), caiadores, moços de recado, vassoureiros etc. (BELTRÃO, 2008). Para atuar em todas essas e outras atividades, muitas vezes, se precisava de conhecimentos específicos.

O embelezamento da cidade, com suas grandes fachadas e gradis suntuosos, também exigia artífices talentosos e preparados, mas ela não dispunha de tais profissionais. Dessa forma, pensou-se no ensino profissional como uma solução para dar uma ocupação útil às pessoas mais pobres que perambulavam pelas ruas, com tabuleiros na cabeça, destas tirando toda a sofisticação que as reformas haviam produzido, ao mesmo tempo em que se atendiam às demandas de conhecimentos especializados para o desenvolvimento da Província; por isso, nesse sentido, o ensino profissional passou a ser grandemente valorizado.

O ensino profissional não foi algo típico da segunda metade do Oitocentos, pois, ainda no Período Colonial, a "educação profissional era prioritária para o aprendizado de ofícios mecânicos que pudessem servir de ocupação e de sustento" (FONSECA, 2008, p.535), mas é "com o positivismo e a força revolucionária das teorias evolucionistas" (RIZZINI, 2008, p.46), que as iniciativas acerca de uma educação de artes e oficios tomam outro fundamento. Prova disso é a construção de lugares específicos para se ministrar a educação profissional. Enquanto, no Periodo Colonial, a educação profissional "fazia-se por meio do envio das crianças para os mestres e mestras de oficio, com os quais aprenderiam a garantir o seu sustento" (FONSECA, 2008, p.539), no Oitocentos, ela acontece em instituições específicas.

É nesse contexto que o ensino profissionalizante assume um caráter mais formal, tudo com vistas à execução eficiente de um projeto de nação livre das amarras de seu passado colonial (RIZZINI, 2008). Para isso, uma das ideias pensadas foi a "fundação de grandes estabelecimentos totais' de internamento e de segregação da sociedade para crianças e adolescentes carentes e sem-família." (MARCíLIO, 2006, p. 206) que, por meio da educação profissionalizante, forneceriam a mão de obra necessária para o desenvolvimento do Brasil. E sse contingente poderia inclusive ser utilizado na nascente industrialização brasileira que carecia de pessoas preparadas para os mais diversos ofícios.

As autoridades consideravam, também, que a permanência dos meninos nesses institutos de formação de artífices se associava perfeitamente aos anseios civilizatórios, já que se apresentava como alternativa para que eles não se envolvessem em atividades ilícitas (UJIIE; PIETROBON, 2008).

250

Ver a E ducação, v. 12, n. 2, p. 247- 270, jul./ dez. 2011 
Segundo Bercho (2009, p.19), a escolha do modelo asilar não foi mera coincidência, muito ao contrário, ele era visto "como um espaço único para a disciplina do corpo" e tinha "como objetivo educar, formar, proteger e corrigir menores abandonados" (MARCÍLIO, 2006, p.208), e a profissionalização era considerada "o meio ideal para desenvolvimento do hábito e do amor ao trabalho e como uma forma de preparar meninos e meninas, para serem úteis à sociedade" (MARCÍLIO,p.214). A principal vantagem desse sistema era que ele proporcionava a inclusão social de forma regulada ao se direcionar a um contingente populacional específico, ao qual era capaz de dar assistência e servir de "medida de controle social” (GONDRA; SCHUELER, 2008, p.108). Com relação a isso, Quiroga (2010) diz que, no Brasil, a implementação do modelo de atendimento filantrópico possuía características mais elitistas e conservadoras, se comparado com os desenvolvidos em outros países.

A instalação do I nstituto Paraense, em paralelo ao crescimento das demandas promovidas pela BelleÉ poque assim como pelas transformações da cidade, é um exemplo da tentativa da elite governante da Província de "enquadrar os homens livres pobres à ordem social como trabalhadores no processo de formação do mercado livre na província paraense" (BEZERRA NETO, 1996, p. 45). Segundo Rizzini (2004, p. 305), "a escassez de braços na Província, a perspectiva da abolição do elemento servil e a expectativa de que os desvalidos fossem úteis à Província e as suas familias, compunham as justificativas para a criação da instituição educacional".

Internatos como o Instituto Paraense se constituíram em solução para "retirar a criança do seu meio deletério e educá-la para a nação que se idealizava" (RIZZINI, 2009, p. 71), representando uma nova forma de socializar adequadamente os meninos, já que, entre seus muros, simulava-se uma nova sociedade na qual "as crianças foram induzidas a um novo mecanismo de organização do viver através da implementação do comportamento social burguês" (BERCHO, 2009, p. 21); ou seja, os artífices aprenderiam a viver, posteriormente, fora dos muros institucionais sem causar grandes problemas às autoridades. E sse era, aliás, um dos grandes sonhos nacionais: a construção de uma ordem civilizada (GONDRA, 2003). Para isso, a filantropia tornava-se uma ideia bem atrativa, principalmente para a elite nacional, já que seus adeptos "passam a constituir uma espéciededite pensante no país que atua[va] no que para eles se constituía a modernização de concepções e instituições sociais de diferentes áreas e domínios." (QUIROGA, 2010, p. 8. Grifos da autora).

E ssa elite "enxergava a população como composta por seres primitivos e bárbaros" (RIZZINI, 2009, p. 87) e acreditava que o ideal filantrópico "permitiria exercer um melhor controle sobre a sociedade" (MARCÍLIO, 2006, p. 206), o 
que, sem dúvida, era muito oportuno na preparação do homem higiênico, bom trabalhador e, principalmente, disciplinado (MARCÍLIO, 2006, p.207). Para isso, os filantropos colocam "os conhecimentos técnico-científicos como o fundamento de sua ação [...]" e realizam "uma poderosa articulação entre saber e poder" (QUIROGA, 2010, p.7). As principais consequências disso são as hierarquias e a divisão de poderes que se manifestavam na organização e na utilização dos espaços internos do asilo (SCHUELER, 2000). É por conta disso que podemos afirmar que "a matriz filantrópica permanece extremamente impregnada de valores morais em relação ao que o grupo de 'esclarecidos' considerava como as formas corretas de condução da vida pessoal, familiar e social dos atendidos" (QUIROGA, 2010, p.9).

Tais formas passam a estar presentes em todas as iniciativas propostas płos intelehuais da modanidadę inclusive na própria estrutura e organização dos estabelecimentos de atendimento. Bercho, discorrendo sobre a finalidade dos espaços físicos dessas instituições, afirma que eles eram pensados para produzir uma ordem onde os educandos

[...] deveriam mover-se segundo a obediência de um tempo não menos rígido e calculado. 0 controle do tempo era essencial para o bom andamento das atividades diárias. Uma vez que os alunos tivessem regras para cumprir no decorrer do dia, se mantivessem ocupados, não sobraria tempo nem espaço para a sociedade ou para o desenvolvimento de vícios prejudiciais ao desenvolvimento físico e moral dos alunos (BERCHO, 2009, p. 20).

A admissão da criança no Instituto significava uma verdadeira separação entre o menino e sua família; uma separação não apenas espacial, mas de comportamento e atitudes. A o regressar para sua comunidade original, essemenino deveria estar completamente moldado e assumir uma postura diferente em família. Isso acontecia porque, ao longo do tempo em que as crianças permaneciam internadas, eram doutrinadas por meio de "atividades moralmente corretas quanto aos preceitos higiênicos de educação" (BERCHO, 2009, p.21), muito distante dos modos de viver das populações mais carentes.

Como dito anteriormente, o Instituto também fazia parte de um processo que se propunha a civilizar a Amazônia. Mas que civilização era pretendida? Para Castanha, a civilidade é o ponto de chegada quando já se superaram a barbárie e a selvageria, características mais contundentes de um estado de desordem. Segundo esse autor, é civilizada a nação que consegue contribuir "para a construção de uma sociedade ordenada e hierarquizada, onde os indivíduos saberiam quais eram os

252

Ver a E ducação, v. 12, n. 2, p. 247- 270, jul./ dez. 2011 
espaços que poderiam e deveriam ocupar." (CASTANHA, 2006, p.17). Gondra e Schueler afirmam que civilização é

[...] o autocontrole e a introjeção de determinados hábitos e normas de conduta, de formas de comer, vestir, morar, conversar, amar e sentir, [e] passou também a expressar os niveis de desenvolvimento artístico, teológico, econômico e científico da humanidade, numa perspectiva claramente etnocêntrica, que conferia superioridade à civilização ocidental européia (GONDRA; SCIIUELER, 2008, p. 69).

Portanto, a civilidade, que é o atributo que a educação buscará incutir no cidadão para fazê-lo civilizado, deve ser "entendida como o controle de emoções e formação disciplinada como um todo." (VEIGA, 2002, p.95). Esse conceito civilizador foi altamente influenciado pela ideia de filantropia que produziu um verdadeiro redirecionamento no foco de interesse da assistência social, que se desloca da salvaçãoda alma para a "sal vação do corpo e da sociedade." (RANGEL, 2010). Martins (2004, p.26) ratifica isso, quando afirma "que o assistencialismo no Brasil, até o século XIX, configurava-se nas ações das instituições religiosas de cunho caritativo que carregavam uma dupla função: a piedade e a proteção da moral social". Assim, as iniciativas antes motivadas pelos caritativos valores cristãos passam a ser empreendidas pelo Estado. A filantropiail passa, então, a qualificar o socorro aos necessitados, que deixa de ser uma virtude cristã para ser uma virtude social; a generosidade passa a ser compreendida como um valor próprio do homem bem-nascido.

A maior diferença entre os conceitos de filantropia e caridade é a motivação. A caridade, mais relacionada aos ideais cristãos de amor ao próximo, pede a renúncia da vaidade de quem a pratica; já a filantropia, ao contrário, tem no desejo da publicização do ato generoso cometido seu principal foco, pois é justamente essa divulgação que dará a visibilidade necessária à obra praticada, servindo de exemplo, ou motivo de honraria. Outra diferença era que, até então, a Igreja havia praticado a assistência social muito mais que o Estado, mas esse quadro começa a ser alterado porque, agora, o governo assume uma postura mais atuante (OLIVEIRA, 2005).

Pela leitura dos relatórios (dos presidentes da Província, dos diretores do Instituto e dos diretores da Instrução Pública) e de leis sancionadas no periodo delimitado neste estudo (1870-1889), constata-se quão fortes foram os sentimentos filantrópicos que motivaram os cidadãos a se interessar pelo atendimento às crianças desvalidas, mesmo com muitas dificuldades em operar, na prática, suas ações. 
A ideia de fundação de um instituto de educandos para o ensino de ofícios mecânicos foi apresentada à A ssembleia Provincial pelo Presidente da Província do Pará, João Alfredo Correa de Oliveira, quando afirma já haver encarregado o titular da Secretaria de Obras Públicas de projetar essa instituição, "na qual o orphão e o filho do pobre recebessem instrução primaria, e aprendessem convenientemente as diversas artes á que se quisessem dedicar segundo as aptidões manifestadas" (GRÃO-PARÁ. RPPP, 1870, p. 22. Grifos nossos).

Segundo Bezerra Neto (1996), João Alfredo só não conseguiu fundar o instituto pretendido por conta das dificuldades orçamentárias impostas pelos recursos limitados do tesouro público provincial, o que levou, inclusive, quando a instituição foi fundada, à diminuição do número de educandos (de 50 para 30), como se previu, inicialmente, por meio da lei provincial de criação do estabelecimento. Essas dificuldades também atrasaram o início das atividades do Instituto em quase dois anos.

A motivação para atender a população a que se destinava o estabelecimento era tão grande que a abertura das matriculas contou com anúncios públicos (JOR XAL DO PARÁ, 02/06/1872), o que demonstra o grande interesse das autoridades provinciais de atingir o público-alvo a ser efetivamente alcançado e, também, deixa claro que as autoridades provinciais, de alguma forma, entendiam serem os periódicos importantes instrumentos de comunicação com as pessoas.

A segunda situação que demonstra a importância do Instituto para a Província é a sua festa de inauguração. O Jornal doPará publicou uma detalhada matéria sobre o ocorrido, na qual diz que a inauguração contou com a presença das autoridades mais importantes da Província, que discursaram exaltando a relevância daquela iniciativa. A reportagem não se furta em descrever o prédio e elogia, especialmente, a localização. O banquete ofertado também não é esquecido, assim como os diversos brindes levantados durante a sua degustação.

Mas esse não foi o único momento de exaltação do estabelecimento. Posteriormente, as autoridades não cessaram de relembrar as elevadas expectativas que tinham com essa instituição e o impacto que ela poderia causar na Província paraense. Os periódicos informam que eram constantes os visitantes ilustres, como os presidentes da Província, que iam, quase sempre, com o objetivo de averiguar como transcorria o atendimento. Outros anúncios e matérias publicadas tratavam das festividades e cerimônias para as premiações anuais, como aparece na reportagem do jornal a seguir:

Teve logar ante-hontem n'este estabelecimento publico de instrucção mechanica e solemnidade de distribuição dos premios aos alumnos, que mais se distiguiram no anno

\section{4}

Ver a E ducação, v. 12, n. 2, p. 247- 270, jul./ dez. 2011 
lectivo, assisjindb ao ado o Exm Sr. Presidate da Proinda e

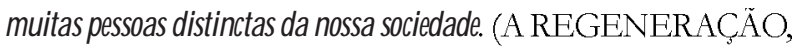
27/12/1874. Grifos nossos).

Até mesmo membros da família imperial, como o Conde D'Eu, estiveram em visita ao Instituto. Os relatórios apresentados à Assembleia Provincial contêm muitas das falas acerca do Instituto, após essas visitas, como, por exemplo, o de 5/11/1872, em que o Barão de Villa da Barra observa que, apesar estar instalado há apenas quatro meses, o Instituto já "promette prestar á província relevantes serviços, sendo de máxima utilidade a seus filhos que se vão applicando ás artes e officios mecânicos" (GRÃO-PARÁ. RPPP, 1872, p.21). Da mesma forma, em seu relatório de 18/04/1873, o Barão de Santarém não se furtou a dizer que o Instituto "continua a funcionar regularmente e promette os benefícios que se deve esperar de sua instituição." (GRÃO-PARÁ. RPPP, 1873, p.10).

Cinco meses depois, outro Presidente, seguindo a linha de seus antecessores, afirma que o Instituto é um estabelecimento que "vae progredindo de modo satisfactorio" (GR ̃OO-PARÁ. RPPP, 1873, p.29), sendo que o Instituto dentre "todas as instituições creadas no intuito de promover a instrucção publica, é [esta] sem duvida das poucas que nos apresenta debaixo d'um ponto de vista mais util á sociedade, pelos vantajosos resultados que della se deve esperar" (GRÃO-PARÁ. RPPP, 1873, p.28) e pelo fato de ser o único "habilitado a constituir artistas dstindos eamstradbs' (GRÃO-PARÁ. RPPP, 1877, p.97. Grifos nossos).

Preparar artistas habilitados era, no entender do presidente Gama Malcher, o principal alvo da formação oferecida naquele estabelecimento. $O$ diretor José Luiz Coelho, em relatório de 1878, escreve que a instituição visava formar mecânicos práticos. Gama Abreu adere a essa ideia, ao afirmar que se destinava a "crear homens praticos e não discursadores" (GRÃO-PARÁ. RPPP, 1879, p.24), mostrando claramente a dicotomia entre trabalho intelectual e trabalho braçal, sendo este último destinado às camadas mais pobres da população. Dessa forma, o Instituto ofereceria "á provincia artistas com habilitações muito superiores ás que até aqui possuíam; e não só habeis, como comhábitos dedsciplina emralidade que, inoculados nos primeiros annos, difficilmente se perderão" (GRÃO-PARÁ. RPPP, 1881, p.57. Grifos nossos).

Os jornais paraenses também apresentaram interessantes opiniões a respeito. Alguns classificavam o Instituto como "uma instituição meritória, de finalidades altruísticas, destinando-se a uma trajetoria brilhante na senda educacional." ( $O$ ARTÍFICE, 03/06/1946). Outros reconheciam que o "desenvolvimento da industria em seus diversos ramos não é sómente uma conveniencia economica de 
ordem muito elevada, é mais do [que] isso, [é] uma palpitante necessidade social de todos os centros da população." (CORREIO DO NORTE, 18/09/1882).

Segundo o Presidente Guilherme Francisco Cruz, o Instituto era um "estabelecimento prometedor de progresso e azylo utilíssimo aos engeitados da fortuna" (GRÃO-PARÁ. RPPP, 1874, p.5). Para Gama Abreu, era uma instituição "d'aquellas em que mais confiança deve ter a provincia" (GRÃO-PARÁ. RPPP, 1881, p.57), por ser

[...] de elevada importancia [para esta]; e si o elemento pedagogico e o scientifico, realmente applicados ao preparo de aptidões sociaes e industriaes forem devidamente considerados [...], serão compensadas as despezas que custao á província e correspondidos os intuitos humanitarios e civilisadores que presidirão a fundação d'ellas. (GRÃOPARÁ. RPPP, 1882, p.7).

A sociedade também fazia vigilância sobre o estabelecimento, como demonstra uma carta de um cidadão, que se identifica como umamigodoprogessa enviada a um jornal paraense, que visitara o Instituto e se dizia muito satisfeito com o que tinha visto, pois encontrara "grande differença no estabelecimento, [...] notando o asseio, ordem e disciplina da casa, gostando sobre tudo muito de ver o respeito e polidez dos novos educandos que pela maior parte são todos de menoe idade." (A PROVINCIA DO PARÁ, 07/06/1879).

\section{A OBRA IMAGINADA E AS DIFICULDADES REAIS DO INSTITUTO PARAENSE DE EDUCANDOS ARTÍFICES PARA FORMAR CIDADÃOS MORIGERADOS}

O ano de 1874 é o primeiro em que um Presidente apresenta as dificuldades vivenciadas com aquele estabelecimento. Ele informa que, ao assumir a presidência da Província, ao contrário dos seus antecessores, encontrou o I nstituto em situação precária. Antes disso, quando se tratava das condições físicas e infraestruturais do estabelecimento, a maior preocupação era com a ampliação e melhoria do espaço visando a atender um maior número de educandos. Todavia, as solicitações não faziam críticas às condições do estabelecimento. Domingos da Cunha Junior, por exemplo, quando solicita, em 1873, a ampliação dos cômodos do edifício, principalmente aqueles onde funcionavam as oficinas, além de melhoria no espaço da enfermaria e em outros, evita qualquer avaliação comprometedora.

256

Ver a E ducação, v. 12, n. 2, p. 247- 270, jul./ dez. 2011 
Já Vicente de Azevedo, em seu relatório de 1874, afirma que, assim que assumiu a presidência da Província, dispôs-se a visitar o estabelecimento. Confessa, contudo, que se frustrou por não tê-lo encontrado em boas condições. Ele havia obtido boas informações de um estabelecimento semelhante, no Maranhão, e acreditava que iria encontrar o Instituto paraense em melhores condições ou, pelo menos, em condições iguais àquelas disseminadas sobre o Instituto maranhense, principalmente porque a Casa de Educandos Paraense havia servido de modelo à Casa fundada no Maranhão.

A partir desse momento, ainda que elogiando a iniciativa e reconhecendo seu valor, os presidentes não cessam de apresentar todos os pontos precários e suas sugestões para o melhoramento das condições, como na Falla de Sá e Benevides, em que afirma que o Instituto não tem se desenvolvido adequadamente, principalmente por conta das condições físicas do prédio do estabelecimento em grande precariedade (GR ̃̃ PARÁ. RPPP, 1875).

Pelos relatórios presidenciais, constata-se que as solicitações dos chefes de governo não eram atendidas com presteza, já que algumas queixas se repetiam, ao longo dos anos, sem qualquer solução por parte da Assembleia Provincial. Os jornais, também, se apresentavam muito insatisfeitos com a postura da Assembleia e criticavam: "Apellar para a assembléa seria o mesmo que clamar no deserto." (A PROVÍNCIA DO PARÁ, 19/04/1876).

Essas dificuldades com a estrutura física do prédio persistem ao longo de todo o Periodo Imperial, valendo salientar que a maior parte delas nunca foi resolvida plenamente, enquanto outras receberam apenas soluções parciais por parte da Assembleia da Província do Grão Pará. Tais problemas infraestruturais traziam constrangimentos de toda natureza, especialmente porque incidiam sobre o estado sanitário do estabelecimento. Em tempos de higienismo, a avaliação negativa do estado sanitário de uma instituição de caráter filantrópico como o Instituto prejudicava politicamente a imagem do governo da Província. São várias as menções, nos relatórios, acerca dos problemas sanitários.

A enfermaria, inclusive, era um dos espaços mais importantes para se avaliar a qualidade do estado sanitário. Os diferentes relatórios dos diretores apontam que a enfermaria existente era contrária ao modelo ideal necessário para aquele momento de higienismo, talvez porque alguém tenha tido a infeliz ideia "de estabelecer uma officina de cortume" (A PROVÍCIA DO PARÁ, 14/01/1877), bem ao seu lado. Embora em nenhum relatório seja feita uma avaliação completa da enfermaria, pode-se deduzir, pelos melhoramentos propostos nos relatórios presidenciais e dos diretores do Instituto, o estado no qual se encontrava. João Capistrano Bandeira de Mello Filho aponta que ela precisava ser completamente renovada (GRÃO- 
PARÁ. RPPP, 1877), pois a atual "se acha[va] muito mal collocada para ter uma livre ventilação, [assim] como é extremamente acanhada" (GRÃO-PARÁ. RPPP, 1878, Ann.: "REL. IPEA", p.III), sem capacidade de comportar 12 doentes.

As reclamações permanecem, por muitos anos, e somente no Relatório de 2 de fevereiro de 1889 é que o Presidente Pernambuco afirma, finalmente, que a enfermaria "está em boas condições hygienicas" (GR ̃̃O-PARÁ. RPPP, 1889, p.44). Coincidentemente, essa avaliação positiva só acontece quando o médico responsável pelo serviço de saúde é substituído, o que provoca dúvidas sobre a veracidade da avaliação, já que, durante todos os anos anteriores, o estado sanitário, em particular o da enfermaria, foi alvo de todas as críticas do Dr. Jayme Bricio.

Em 1878, o Presidente José Joaquim do Carmo ainda aponta a precariedade do estado sanitário do Instituto, embora não diga quais reparos considerava necessários. Outros presidentes, porém, foram bem claros quanto ao que desejavam para melhorar as suas condições higiênicas. Essas propostas estavam focadas, basicamente, nos espaços de convívio dos educandos, como os dormitórios, por exemplo, quase sempre superlotados, além de melhor infraestrutura para a higiene pessoal.

Reivindicava-se a "construcção de dormitorios espaçosos, onde não estejão os educandos como actualmente, agglomerados" (GRÃO-PARÁ. RPPP, 1877, p.102), nos quais "o ar ambiente se ache mais livre e á cada instante mudado" (GRÃO-PARÁ. RPPP, 1878, Ann.: "REL. IPEA”, p.I). Já no que dizia respeito à higiene pessoal, a maior dificuldade era com os banheiros e abastecimento de água para as práticas de higiene básica, pois, quanto aos banheiros, o estabelecimento era mal servido.

O Presidente Bandeira de Mello Filho, foi o primeiro a propor a "construcção de [...] banheiros que possao fornecer banhos freqüentes, visto o uso destes não constituir simplesmente um meio de aceio, porem muito contribuir para a boa saude e vigor dos educandos." (GR ̃̃O-PARÁ. RPPP, 1877, p.102). A prática dos banhos, portanto, era considerada "necessaria á salubridade dos educandos, que d'elles se vêem privados." (GRÃO-PARÁ. RPPP, 1880, p.43) por conta da ausência de um bom poço com bomba.

Em 1881, o diretor do Instituto, em relatório encaminhado à presidência, informa que "[até] esta data não tem ainda o estabelecimento um poço nem um banheiro capaz para os educandos" (GRÃO-PARÁ. RPPP, 1881, Ann.: "REL. IPEA", p.LIII). Segundo esse Reatóiio.., o médico do estabelecimento, também, salienta a necessidade da "construcção de, pelo menos, 2 grandes banheiros" (p.LXIV), pois, segundo ele, no "estabelecimento póde-se dizer que nem um poço ha, visto que o que existe, além de péssima agua, não a fornece em quantidade

258

Ver a E ducação, v. 12, n. 2, p. 247- 270, jul./ dez. 2011 
sufficiente" (p.LXIV). Reivindicava-se, também, "a construç̧ão de duas latrinas inglezas, com tubos conductores que levem as materias fecaes para o competente deposito, que deve ter respiradouro. Em cada latrina deve existir un deposito d'agua para lavagem e asseio das mesmas." (p.LXV).

Ao dirigir-se à A ssembleia Provincial, o Presidente $G$ ama A breu apresenta essa necessidade e solicita recursos para melhoramentos nessa área e alerta que, de acordo com a recomendação médica, "é preciso estabelecer banheiros e bôas latrinas, o que, se me concederdes verba, será executado." (GRÃO-PARÁ RPPP, 1881, p.56). Pelos relatórios presidenciais, pode-se deduzir que, a despeito dos apelos, a Assembleia Provincial não se comoveu, pois, anos depois, outro Presidente ainda solicitava: "Que sejão construidos dous banheiros e latrinas inglezas." (GRÃO-PARÁ. RPPP, 1885, p.27). Essa solicitação é feita também pelo diretor do Instituto, em 1886, ao afirmar que o estabelecimento precisava "de um banheiro mais espaçoso e hygienico [...] afim de se poder conservar a disciplina e moralidade entre os educandos." (GRÃO-PARÁ. RPPP, 1886, Ann.: "REL. IPEA", p.86). Esse problema não foi resolvido, pois, constantemente, ele reaparece nos relatórios presidenciais, até fins de 1889.

Outro objeto de reivindicação, nos relatórios presidenciais e nos dos diretores do Instituto, era o almoxarifado, o local onde todos os pertences do Instituto eram guardados e funcionava a própria administração. Não à toa, já em 1874, o Presidente apontou a necessidade de "ampliar o depósito do almoxarifado [...] já insufficiente para comportar as obras preparadas nas oficinas." (GR ̃̃OPARÁ. RPPP, 1874, p.29). Nos anos posteriores, as reclamações continuaram, e, em 1879, o Presidente ainda continua a apontar a necessidade de reformas no almoxarifado, pois, em relatório remetido a ele pelo diretor do Instituto, aquele espaço encontrava-se em péssimo estado e era inadequado para os seus fins. Finalmente, no ano de 1880 , foi construído um novo almoxarifado que, em 1885, sofreu nova reforma. A despeito disso, as críticas à estrutura do setor e à necessidade de melhorá-lo permaneceram, pois, em 1889, ainda se referiam à necessidade de ampliar e melhorar suas condições.

Todas essas dificuldades comprometiam a execução dos fins do Instituto, como vimos anteriormente. Afora esses objetivos, existia um que, embora não aparecesse formalmente, era o grande desejo das autoridades imperiais: una sociedade morigerada "definida como uma produção de indivíduos estética e politicamente saudáveis" (NICOLAZZI, 2000, p.2. Grifo do autor). Portanto, estabelecimentos como o Instituto Paraense eram, sem dúvida, espaços privilegiados para esse processo de doutrinação, pois a "preparação da mente e do corpo para o trabalho deveria começar nos primeiros anos de vida, pois a 
infância era considerada a fase da vida ideal para formar o caráter das pessoas." (MARIN, 2006, p.122).

O vocábulo morigerado aparece, pela primeira, vez no Relatório Presidencial, de 1870, que, coincidentemente, é também o relatório em que o Instituto é citado pela primeira vez. Nele, o Presidente João Alfredo afirma que o estabelecimento produziria os bons artistas de que a Província tanto precisava, mas forjaria também "cidadãos morigerados" (GRÃO-PARÁ. RPPP, 1870, p.22). 0 termo está relacionado, desde o início, ao Instituto Paraense de Educandos Artífices, lousda "socialização para o trabalho [e que] seria capaz de dignificar e transformar a existência das pessoas, de modo a orientálas para a edificação do bem individual e social" (MARIN, 2006, p.122). Esse termo aparece, ainda, mais sete vezes, em outros relatórios presidenciais, para classificar os educandos que melhor se adaptavam ao processo educativo e que, por isso, recebiam, inclusive, distinção sobre os demais.

Embora, hoje, a palavra morigerância seja pouco usual, no século XIX, os governantes e autoridades costumavam usá-la para se referir a um coletivo de sujeitos considerados preparados para desenvolver o país. No entendimento da época, morigerada era a pessoa doutrinada para agir e reagir de uma determinada forma. Poderiam ser chamados assim aqueles homens "que compartilhavam do ideário da positividade do trabalho e da acumulação. Também eram morigerados aqueles que sabiam comportar-se dentro de determinadas regras de etiqueta consideradas civilizadas." (PEREIRA, 1996, p.12).

Marin (2006, p.127), discorrendo acerca do ensino profissionalizante oferecido à infância desvalida na Colònia Blasiana (Goiás), diz que o processo de morigeração da sociedade feito nas instituições profissionais voltadas para a infância desvalida pretendia formar homens morigerados, ou seja, "capazes de trabalhar para o engrandecimento da pátria", transformando os "indivíduos em cidadãos solidários ao ideário burguês" (NICOLAZZI, 2000, p.2), pois tinha o objetivo tornar as pessoas trabalhadoras aptas a contribuírem para o desenvolvimento do país.

Dessa forma, os morigerados, que tanto se desejava formar no Instituto de Educandos, seriam aqueles cidadãos cooperativos, que se submeteriam a toda e qualquer condição e situação sem fazer reclamações ou reivindicações, agindo sempre com a devida civilidade, e, porque não dizer, docilidade, pois o mais importante era que, independentemente de quaisquer inconvenientes e/ou limitações, os sujeitos trabalhassem de forma prestativa e laboriosa. (GILLIES, 2007).

Assim, cabia aos meninos matriculados no estabelecimento "obedecer ao diretor e aos demais funcionários, mostrando-se sempre atentos aos seus conselhos e às suas advertências." (MARIN, 2006, p.121). A formação dada por meio das

260

Ver a E ducação, v. 12, n. 2, p. 247- 270, jul./ dez. 2011 
aulas e oficinas era uma das formas de se alcançar esse objetivo; o controle sobre o comportamento era outra. Na verdade, tudo o que era executado ou pensado dentro do Instituto tinha como propósito principal favorecer a concretização desse objetivo (o alcance da morigerância), visando atender às demandas sociais.

Para incentivar ainda mais a morigerância, ao cursar as disciplinas e oficinas do Instituto, um educando poderia, além do aprendizado teórico e prático, adquirir uma menção especial por apresentar-se mais capacitado que os demais em algum aspecto, pois fazia parte do regulamento daquele estabelecimento a distinção por meritocracia. A premiação, presente desde o primeiro Regulamento do Instituto (1872), era concedida em três categorias: "capacidade moral, capacidade intellectual e capacidade industrial" (Art.94), distribuídos os prêmios a partir de determinados critérios e de acordo com procedimentos específicos.

Segundo esse Regulamento, o prêmio consistia numa medalha de prata com a inscrição da categoria a que se referia e conferia, a quem a recebesse, al to grau de distinção, tanto que deveria ser "trazida pelo premiado, todas as vezes que sair á rua, e nas occasioes de formatura do corpo" (Art.96).

O prêmio por capacidade intelectual resultava da avaliação de aproveitamento dos alunos feita pelos professores nas aulas ofertadas, ou na chamada parte teórica. O prêmio por capacidade moral decorria da observação da conduta do educando, no dia a dia do estabelecimento, de sua morigerància, conceito que era extremamente valorizado e merecedor de todo reconhecimento. Para escolher o educando que receberia esse prêmio, era formado um júri composto pelo agente, pelo escriturário e pelo almoxarife do estabelecimento. Já o reconhecimento por capacidade industrial relacionava-se à perícia apresentada por um educando na manufatura dos diferentes produtos ensinados pelos mestres nas oficinas do Instituto. A qualidade do trabalho concluido e um conjunto de características observadas eram os critérios que os mestres usavam para apontar os educandos mais habilidosos nos seus respectivos ofícios.

A atribuição dos prêmios era muito rigorosa, tanto que, caso os educandos não atingissem os critérios considerados mínimos para ter direito a elas, não a receberiam de forma alguma. Um exemplo disso é que, no ano de 1875, "por não ter nenhum dos educandos apresentado uma obra de primor" (GRÃO-PARÁ. RPPP, 1875, p.37), ninguém recebeu o prêmio de capacidade industrial.

Os prêmios faziam parte da realidade das instituições de abrigamento pelo seu intenso caráter meritocrático. Segundo Marin (2006, p.125), a "premiação [...] visava distinguir e valorizar os alunos interessados em aplicar os ensinamentos repassados pela instituição". Pela leitura dos relatórios, deduzimos que a entrega dos prêmios era feita em circunstâncias festivas, patrocinadas pelo tesouro provincial. 
No entanto, em 1879, isso começa a mudar, já que o Presidente da Província determina que o valor dispensado para a comemoração deveria sair do caixa do próprio Instituto e não do tesouro provincial, como acontecia anteriormente (GR ̃̃O-PARÁ. Officio de 10 de Janeiro de 1879).

Além das premiações, a rotina do Instituto também possuía outras práticas para diferenciar os educandos uns dos outros. Independentemente da forma, a morigerância ainda era o critério principal. Ela possibilitava, por exemplo, que os meninos adquirissem o direito de assumir uma liderança sobre os demais. De acordo com os relatórios presidenciais, era comum que os educandos fossem divididos em três ou quatro grupos, e cada um tivesse um educando "tirado d'entre os mais idôneos e morigerados" (GR ̃̃O-PARÁ. RPPP, 1875, p.35) para supervisioná-lo.

Outra forma de distinção se dava quando os educandos atuavam nas várias funções daquele estabelecimento. Eles eram escolhidos por serem os mais aptos, mas também por serem os mais morigerados. O exercício de uma função implicava total diferenciação, na rotina do educando, assim como acesso a espaços vedados aos demais, como o almoxarifado e a despensa, por exemplo. Esses meninos, também, conviviam mais com os funcionários do que com seus pares, criando relações diferenciadas, no contexto institucional.

De acordo com o primeiro Regulamento do Instituto Paraense de Educandos Artífices (1872), o cargo de agente bem como os empregos de fiel, amanuense e enfermeiro poderiam ser exercidos por educandos que mostrassem aptidão e capacidade (GRÃO-PARÁ. IPEA, 1872, Art.87). O Regulamento acrescenta, também, que o diretor tinha a prerrogativa de "nomear temporariamente um educando dos mais idoneos para auxiliar o serviço de escripturação do almoxarifado e expediente" (Art.87).

A organização do espaço físico também deveria ajudar no controle. Não foram poucas as solicitações para que o terreno ao redor do prédio do Instituto fosse murado, já que "um estabelecimento d'estes é sempre cercado de muros" (GR ÃO-PARÁ. RPPP, 1881, Ann.: "REL. IPEA", p.LII). Diferentes presidentes insistiram nessa obra o que demonstra que ela era de extrema necessidade para a vigilância. A delimitação do espaço proporcionada por um muro, controlando, assim, o acesso do e ao meio externo, era tida como garantia de melhor controle e disciplina. As reivindicações eram que se murassem "as suas faces lateraes, afim de se poder conservar a disciplina e moralidade entre os educandos" (GR ÃOPARÁ. RPPP, 1885, Ann.: "REL. IPEA", p.86).

Os registros mostram que a vigilância deveria ser realizada, em todos os momentos, desde as refeições até a hora de dormir, pois uma das medidas

262

Ver a E ducação, v. 12, n. 2, p. 247- 270, jul./ dez. 2011 
requeridas era "também fechar os alojamentos, de modo a evitar-se que os educandos ausentem-se durante a noite" (GRÃO-PARÁ. RPPP, 1874, p.28). Outra preocupação era que os meninos pudessem se envolver sexualmente, já que a adolescência, fase em que a maioria se encontrava, é uma época típica para tais descobertas. Quando o número de educandos chega aos 123, o Presidente classifica-o de excessivo e alerta não ser "possivel conservar [ahi] tão grande numero de menores, obrigados a dormirem no mesmo leito, aos dois e aos três, contra todas as regras da hygiene por falta absoluta de acomodações" (GR ÃO-PARÁ. RPPP, 1889, p.11). Essa preocupação pode ser mais bem entendida quando articulada à informação dada pelo Dr. Jayme Pombo Bricio, em seu relatório médico, que anexa um quadro demonstrativo das enfermidades tratadas em que constam referências à existência de educandos acometidos de doenças venéreas.

As punições a que estavam sujeitos os educandos não previam os castigos físicos, no entanto, não se pode afirmar, com certeza, que eles não eram aplicados, pois consta que, em determinado momento, o Presidente da Província foi informado que os mestres das oficinas usavam desse expediente para com os educandos; por isso, cobra esclarecimentos e sentencia "recomendo a vmc., que caso de ser isto exacto, haja de prohibir semelhante uso, que essa directoria jamais consentirá." (A CONSTITUIÇÃO, 13/02/1886).

Segundo Irma Rizzini (2004), os castigos físicos há muito haviam sido abolidos da maioria das províncias brasileiras, inclusive a paraense; mas a pesquisadora encontrou, em suas investigações, uma grande quantidade de documentos em que os pais informam e reclamam dos castigos aplicados aos seus filhos pelos professores. Quanto ao Instituto, não foi encontrada, nem antes nem depois dessa data, qualquer menção a esse tema. Também não foi encontrada, por parte do diretor, qualquer resposta (negação ou justificativa) quanto à solicitação que o Presidente fazia.

Seja como for, a questão da disciplina era muito importante e precisava ser aplicada a qualquer custo, pois se acreditava que, mesmo não sendo possível "fazer comprehender aos meninos as razões pelas quaes tal ou qual preceito the é imposto; entretanto, com aquelles de uma certa idade haverá fructo nisto." ( $O$ MONTE ALEGRENSE, 21/03/1886).

\section{CONSIDERACÕES FINAIS}

A partir dos anos de 1850, depois de várias crises financeiras e das revoltas regenciais em, praticamente, todas as regiões do país, o Império vive uma fase de consolidação política. Mais do que nunca, as propostas pensadas nos anos 
anteriores começam a ser experimentadas, dentre elas, a aliança entre educação e assistência social.

Esse período é tão fértil que nele pode-se observar uma verdadeira ampliação geográfica da educação popular, assim como o surgimento, em todo o território nacional, de dezenas de asilos, escolas e institutos, que se apresentavam como alternativas ao modelo escolar tradicional e se direcionavam para públicos específicos. Os institutos, por exemplo, eram destinados, principalmente, à formação profissional, oferecendo instrução nas artes e ofícios aos meninos desvalidos.

N a A mazônia, as ideias iluministas, pelo menos no plano do imaginário governamental, chegam com força total. A educação passa a ser difundida como o melhor caminho para a Província do Grão Pará chegar à condição de civilizada, em pé de igualdade com a capital e mesmo com os países do continente europeu. $\mathrm{E}$ nesse momento, também, que se começa a discutir como esse processo civilizador deveria ser oferecido à população, com base em uma dada representação dos povos amazônicos, sua origem e história. A miscigenação, no bojo dos debates sobre povo e educação, passa a ser considerada a principal responsável pelo atraso no qual se afirmava viver o amazônida, uma gente de arco e flecha. Esse pensamento era comum na maioria dos governantes e grupos militares.

Em 1872, foi fundado o Instituto Paraense de Educandos Artífices, uma resposta dos governantes à modernidade que já havia chegado à capital da Província, trazida, principalmente, pelos vultosos recursos que começavam a circular no comércio belenense, com a expansão da exploração da borracha. Ele foi destinado ao atendimento de crianças e jovens desfavorecidos. Sendo uma instituição que se enquadrava na nova mentalidade do final do século 19 , que metamorfoseava a assistência social de face caritativa, ligada principalmente aos ideais religiosos, à filantrópica, de caráter mais científico, atrelada aos ideais do iluminismo. O Instituto também se apresentava como uma proposta civilizadora da população local, principalmente a mais pobre, marcada pela mestiçagem, fortemente rejeitada pelos governantes.

Esse estabelecimento visava atender, também, à necessidade de se constituir uma força de trabalho que garantisse o atendimento de todas as demandas forjadas no dia a dia da BelleÉ poquedos trópicos, pois, à medida que os anos passavam, crescia a demanda por labutadores cada vez mais especializados. Mas, além da formação profissional, se queria também que os homens instruídos fossem doutrinados para adquirirem o verdadeiro sentimento de amor ao Brasil, principalmente de amor ao trabalho, contribuindo voluntariamente para a construção e o desenvolvimento do país. Esses homens seriam morigerados, ou seja, aqueles que compreendiam 
perfeitamente o seu lugar no processo produtivo e não procuravam outro espaço de atuação, ficando satisfeitos com o que tinham.

Alguns homens das letras acreditavam que, para uma melhor morigeração, as pessoas precisavam ser doutrinadas desde pequenas; por isso, a idade inicial de admissão ao Instituto era de sete anos. Além disso, fazia-se necessário submeter os meninos à mais rigida disciplina para que, desde cedo, eles não tivessem dificuldades relacionadas à insubordinação.

$N$ ão à toa o regime disciplinar controlava todo o dia deles, inclusiveo tempo considerado livre, e era praticamente uma reprodução dos regimentos disciplinares militares, pois se utilizavam de várias práticas, típicas do militarismo, como uso do uniforme, exercícios militares, atividades físicas etc.

Os educandos só podiam sair do Instituto devidamente autorizados e, mesmo quando fora do estabelecimento, ainda estavam sujeitos a várias normas, como a de não falar com estranhos, por exemplo, entre outras. Em contrapartida, o próprio regime disciplinar encontrava formas de compensar a rígida disciplina com prêmios e distinções concedidas a cada ano aos meninos que se destacavam nos aspectos valorizados pela direção e pelo corpo de funcionários do estabelecimento.

Assim, o Instituto assumia um importante papel na sociedade paraense: o de formar homens e profissionais úteis a si mesmos e à nação, além de desenvolver indivíduos perfeitamente ajustados à sociedade e dóceis. Garantia-se, assim, que os meninos não se entregassem aos vícios e imoralidades tão repudiadas à época.

Pelos relatórios dos presidentes da Província e dos diretores do estabelecimento, os fins almejados se materializavam na organização pedagógica e curricular, pois tudo era pensado para se garantir os objetivos propostos.

A jornada pedagógica, segundo os regulamentos do Instituto Paraense, ocupava os meninos, de dia e à noite, com diversas atividades formativas; entre estas, destacamos as orações, realizadas em diferentes momentos do dia. E ssas e outras atividades religiosas, oriundas das tradições da Igreja Católica, eram mais um ingrediente na receita da morigerância. No mais, tudo tinh hora predeterminada, controlada pelo ressoar da sineta, eisso era fundamental para o controle dos corpos e das mentes dos educandos.

A pesar dos investimentos considerados altos, o Instituto Paraense não chegou a causar grande impacto na vida das camadas mais pobres. Primeiro, porque o número de meninos atendidos, ao longo dos seus quase trinta anos de funcionamento durante o Período Imperial, foi muito reduzido, não chegando nem a mil e quinhentos meninos, número insignificante diante do quantitativo de crianças desvalidas existentes na Província, como apontam os relatórios da diretoria da instrução pública e como comprovam as insistentes solicitações de ampliação do número de educandos. 
Segundo, por não ter atendido às crianças indígenas, historicamente muito exploradas nas mais diversas atividades nas ruas da capital e nas casas dos homens ilustres. Quanto às crianças ingênuas e libertas, também tiveram um número de atendimentos quase insignificante, mesmo sendo essas as principais vítimas da pobreza daquela época.

Mas para os meninos atendidos e suas famílias, a passagem pelo I nstituto foi um diferencial em suas vidas, pois, ao saírem do estabelecimento, os educandos tinham uma profissão especializada, o que favorecia encontrar mais facilmente uma colocação no mercado, prova disso é que alguns dos oficiais retomavam ao Instituto como mestres das oficinas.

Embora não se tenha dados concretos para afirmar, supõe-se ademais que o pecúlio recebido quando do desligamento auxiliou a muitos daqueles rapazes a iniciarem suas vidas profissionais fora do Instituto e garantirem assim o seu sustento, mesmo que em determinados períodos esse valor não tenha sido assim tão elevado. Portanto, de al guma forma o Instituto, se não causou um grande impacto na situação de pobreza vivenciada na Província do G rão Pará, com certeza causou grandes transformações na vida dos meninos que puderam receber a formação oferecida por ele.

Ao fim e ao cabo, o Instituto foi um instrumento usado na consolidacão do projeto civilizador iniciado desde a conquista da América pelo português e que acabou se transformando em recurso dos homens miscigenados da Província para se manter, ainda que precariamente, ao realizar atividades consideradas de segunda categoria em uma sociedade que, ao longo do século 20 , já na condição de E stado do Pará, servirá ao avanço do capitalismo.

O Instituto foi, sem dúvida, reapropriado pelos filhos da terra, que encontraram nele uma forma de diferenciação eascensão social. Por meio do ensino recebido, os meninos eram apresentados à sociedade em uma nova condição - a de trabalhadores especializados (artífices). Ao assumir tal condição, esses novos trabalhadores passaram a almejar um nível social que, antes, jamais seria atingido apenas por seus esforços, o que pode explicar o grande número de solicitações para a admissão encaminhadas a cada dia ao Presidente da Província.

Apesar de os pais saberem das restrições a que seus filhos seriam submetidos, para muitos meninos e suas famílias ingressar no I nstituto era a única alternativa que se lhes apresentava.

266

Ver a E ducação, v. 12, n. 2, p. 247- 270, jul./ dez. 2011 


\section{NOTAS}

' E stabelecimentos e, ou, instituições totais são locais "onde um grande número de indivíduos com situação semelhante, separados da sociedade mais ampla por considerável periodo de tempo, levam uma vida fechada e formalmente administrada." (GOFFMAN, 1974).

ii Sobre o tema, ver: NASCIMENTO, Denise Raimundo. Fundação Ataulpho de Paiva - Liga Brasileira Contra a Tuberculose: um século de luta. Rio de Janeiro: Quadratim; 2002; MESTRINER, Maria Luiza. Estado entre a filantropia e a assistência social. São Paulo: Cortez, 2001.

\section{REFERENNCIAS}

ARAÚJO, S. M. S. (Org.). José Veríssimo: raça, cultura e educação. Belém: EDUFPA, 2007.

A CONSTITUIÇ̃̃O (Orgão do Partido Conservador). Belém: Typ. da Constituição, [várias edições], 1886.

Belém: Typ. da Constituição, [várias edições], 1877.

A PROVÍNCIA DO PARÁ. Belém: Typ. do Futuro, [várias edições], 1876.

A REGENERAÇÃO. Belém: Typ. d'A Regeneração, [várias edições], 1874.

BEITRÃO, J.F. A andarilha em Belém, cidade do Pará oitocentista. In: VIEIRA JR, A.O. (Org.). Conheça Belém, co-memore o Pará. Belém: EDUFPA, 2008. Disponivel em: <http://www.pdf-2-flashbook.com:8080/viewBook.cfm? $\mathrm{b}=65 \mathrm{fd} 40 \mathrm{~d} 0 \mathrm{ad} 3461 \mathrm{a} 5788643 \mathrm{~d} 549$ af6c89>. Acesso em: 13 jun. 2009.

BERCHO, C.F. Discurso higiênico na formação da educação do Rio de Janeiro imperial: Colégio Pedro II (1829-1850). In: Seminário Nacional de Estudos e Pesquisas, 8. 2009. Campinas (SP). Anais [eletrônicos]. Campinas (SP): Unicamp/ FAE; Histedbr, 2009. Disponivel em: <http://www.histedbr.fae.unicamp.br/acer_ histedbr/seminario/seminario8/_files/3xUrdzwi.doc>. Acesso em: 09 nov. 2009.

BEZERRA NETO, J.M. As luzes da instrução: o asylo de Santo Antonio em Belém do Pará (1870-1912). In: MARIN, R.E.A. A Escrita da história. Belém: NAEA/UFPA, 1998.

. As oficinas do trabalho: representações sociais, institutos e ensino artístico no Pará (1830/1888). Ver A Educação. Belém, v.2, n.1, p. 41-70, jan/jun. 1996. Disponivel em: <http://www.veraeducacao.belemvirtual.com.br/web/revistas/ v2n1_completo.pdf>. Acesso em: 25 maio 2009. 
Andreson Carlos Elias Barbosa

CASTANHA, A.P. Pedagogia da moralidade: a Ordem Civilizatória Imperial. In: Navegando na História da Educação Brasileira, Campinas, HISTEDBR, [http] 2006. Disponivel em: <http://www.histedbr.fae.unicamp.br/navegando/ artigos_frames/artigo_014.html>. Acesso em: 01 maio 2009.

CORREIO DO NORTE. Belém: Typ. de Francisco da Costa Junior; Typ. do Correio do Norte; Typ. C. Wiegandt, [várias edições],1882.

FONSECA, T.N.L. Instrução e assistência na capitania de Minas Gerais: das ações das câmaras às escolas para meninos pobres (1750-1814). Revista Brasileira de Educação. Rio de Janeiro, vol.13, n.39, p. 535-544, set./dez. 2008. Disponivel em: <http://www.scielo.br/pdf/rbedu/v13n39/09.pdf>. Acesso em: 14 set. 2009.

GILLIES, A.M.R. Os Ingleses da Colônia do Assunguy (1859-1882) sob a perspectiva do processo civilizador: um estudo comparativo com outra comunidade britânica do século XIX. In: Simpósio Internacional Processo Civilizador, 10. 2007. Campinas, (SP). Anais. Londrina (PR): UEL: Grupo de Estudos Processos Civilizadores, 2007; CD-ROM. Disponivel em: <http://www.uel.br/grupoestudo/processoscivilizadores/portugues/sitesanais/anais10/Artigos_PDF/ Ana_M_R_Gillies.pdf>. Acesso em: 5 abr. 2011.

GONDRA, J.G. "Modificar com brandura e prevenir com cautela". Racionalidade médica e higienização da infäncia. In: FREITAS, M.C.; KUHLMANN JR, M. (Org). Os Intelectuais na história da infância. São Paulo: Cortez, 2002.

Medicina, higiene e educação escolar. In: LOPES, E.M.; FARIA FILHO, L.M.; VEIGA, C.G. 500 anos de educação no Brasil. 3 ed. Belo Horizonte: Autêntica 2003.

GONDRA, J.G.; SCHUELER, A. Educação, poder e sociedade no Império brasileiro. São Paulo: Cortez, 2008.

GRÃO-PARÁ (Provincia do). Instituto Paraense de Educandos Artífices (IPEA). REGULAMENTO, 1872.

Relatórios dos Presidentes da Província do Pará (RPPP). 1870-1889. In: Provincial Presidential Reports (1830-1930): Pará. Chicago, Il.: Center for Research Libraries]. Disponiveis em: <http://www.crl.edu/brazil/provincial/ par\%C3\%A1>. Acessos [vários] em: 2010.

GUIMARÃES, L.A.V. As casas \& as coisas: um estudo sobre vida material e domesticidade nas moradias de Belém - 1800-1850. 2006. 195 p. Dissertação (Mestrado). Universidade Federal do Pará, Centro de Filosofia e Ciências Humanas, Programa de Pós-Graduação em História Social da Amazônia. Belém (PA), 2006.

JORNAL DO PARÁ (Órgão oficial). Belém: Typ. do Jomal do Pará, [várias edições] 1872.

268

Ver a E ducação, v. 12, n. 2, p. 247- 270, jul./ dez. 2011 
MARCÍLIO, M.L. História social da criança abandonada. São Paulo: Hucitec, 2006. MARIN, J.O.B. Ensino profissionalizante em Goiás: a experiência pioneira da Colônia Blasiana. Inter-ação. Goiânia (GO), v.31, n.1, p.111-137, jan./jun. 2006. Disponível em: <http://www.revistas.ufg.br/index.php/interacao/article/ view/1495/1479>. Acesso em: 5 abr 2011.

MARQUES, V.R.B.; LANGE, S.P. Crianças trabalhadoras: os aprendizes marinheiros no Paraná oitocentista. ASCLEPIO. Revista de Historia de la Medicina y de la Ciencia. v. LX, n. 2, p. 75-94, jul.-dic. 2008. Disponivel em: <http:// asclepio.revistas.csic.es/index.php/asclepio/article/viewFile/258/254>. Acesso em: 13 nov. 2009.

MARTINS, S. D. Reformando a Casa Imperial. As reformas modernizantes da Assistência e da Educação no Império e o exemplo do Asilo de Meninos Desvalidos na Corte (1870-1888) . 2004. 97p. Dissertação (Mestrado em História) Universidade Federal do Rio de Janeiro. Instituto de Filosofia e Ciências Sociais. Programa de Pós-graduação em História Social. Rio de Janeiro, 2004. Disponivel em: <http://www.multiculturas.com/boarding_school/library/SMartins_asilo_ meninos_desvalidos_na_corte_2004.pdf>. Acesso em: 10 set. 2009.

NICOLAZZI, F. A Fabricação do Sorriso. Ortodontia social em Curitiba na virada dos séculos XIX e XX. Klepsidra [Revista Virtual de História]. Ano I, n.3, ago.set. 2000. Disponivel em: <http://www.klepsidranet/klepsidra3/cidadesorriso. html> Acesso em: 05 abr. 2011.

OLIVEIRA, Sidney Benedito. Ação social e terceiro setor no Brasil. 2005. 151p. Dissertação (Mestrado em Economia Política)—Pontifícia Universidade Católica de São Paulo. São Paulo, 2005. Disponível em: <http://www.sapientia.pucsp.br/ tde_busca/arquivo.php?cod Arquivo=1985>. Acesso em: 21 set. 2010.

O ARTÍFICE. (Órgão do Grêmio Cívico-Literário Emesto Matoso). Belém, ano XX, n1.25, 3 jun. 1946.

O MONTE ALEGRENSE. Monte Alegre: [S.n.], 1886.

PEREIRA, M. R. M. Semeando iras rumo ao progresso. Curitiba: Ed. UFPR, 1996.

QUIROGA, A. M. Assistência Social no Rio de Janeiro oitocentista: desqualificação dos atendidos, racismo científico e filantropia. In: Encontro Regional da AnpuhRJ, 14. (Memória e Patrimônio). 2010. Rio de Janeiro. Anais [eletrônicos]. Rio de Janeiro: Anpuh-RJ, 2010. CD-ROM. Disponível em: <http://www.encontro2010. rj.anpuh.org/resources/anais/8/1273270795_ARQUIVO_Versaofinal Anpuh. pdf>. Acesso em: 21 set. 2010.

RANGEL, R.F. A laicização da assistência social na primeira República. In: Encontro Regional da Anpuh-RJ, 14. (Memória e Patrimônio). 2010. Rio de 
Janeiro. Anais [eletrônicos]. Rio de Janeiro: Anpuh-RJ, 2010. CD-ROM. Disponivel em: <http://www.encontro2010.rj.anpuh.org/resources/anais/8/1276742598_ ARQUIVO_artigoANPHU.pdf $>$. Acesso em: 21 set. 2010.

RIZZINI, Irene. O Século perdido. Raízes históricas das políticas públicas para a infância no Brasil. 2 ed. rev. São Paulo: Cortez: 2008.

Crianças e menores - do pátrio poder ao pátrio dever. Um histórico da legislação para a infância no Brasil. In: RIZZINI, I; PILOTTI, F. (Org). A Arte de governar crianças: a história das políticas sociais, da legislação e da infância no Brasil. 2 ed. rev. São Paulo: Cortez, 2009.

RIZZINI, Irma. O Cidadão polido e o selvagem bruto: a educação dos meninos desvalidos na Amazônia Imperial. 2004. 441 p. Tese (Doutorado em História) Universidade Federal do Rio de Janeiro. Instituto de Filosofia e Ciências Socais. Programa de Pós-Graduação em História Social. Rio de Janeiro, 2004.

SCHUELER, A.F.M. A "Infância desamparada" no asilo agrícola de Santa Isabel: instrução rural e infantil (1880 - 1886). Educação e Pesquisa. São Paulo, v.26, 1n.1, p.119-133, jan./jun. 2000. Disponível em: <http://www.scielo.br/pdf/ep/v26n1/ a09v26n1.pdf>. Acesso em: 5 set. 2009.

UJIIE, N.T.; PIETROBON, S.R.G. Considerações acerca do movimento a favor da infância no Brasil: final do século XIX e início do século XX. Publicatio. Ponta Grossa, Ano v.16, n.2, p.335-341, dez. 2008. Disponível: <http://www.uepg.br/ propesp/publicatio/hum/2008-2/Art.12.pdf>. Acesso em: 22 set. 2010.

VEIGA, C.G. A Escolarização como projeto de civilização. Revista Brasileira de Educação [online]. Rio de Janeiro, n.21, p. 90-103, set/out/nov/dez 2002. Disponível em: <http://wwwanped.org.br/rbe/rbedigital/RBDE21/ RBDE21_09_CYNTHIA_GREIVE_VEIGA.pdf>. Acesso em: 13 nov. 2009. 